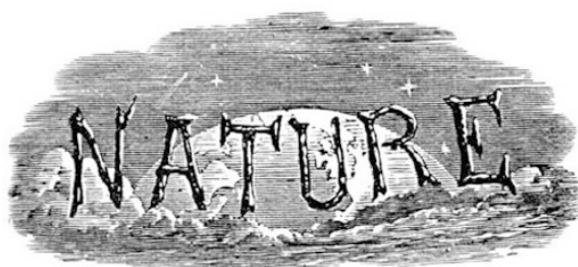

SATURDAY, MARCH 4, 1933

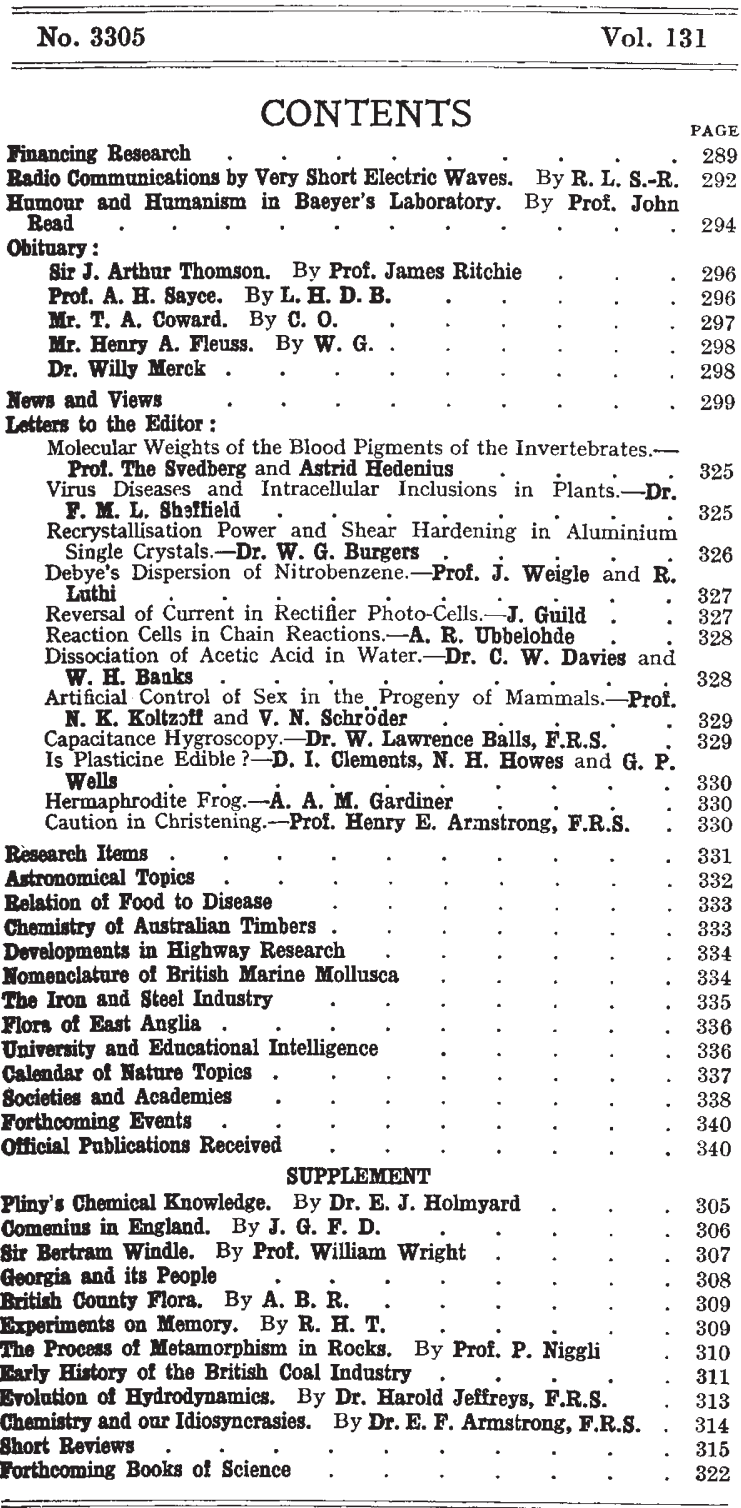

Editorial and Publishing Offices:

MACMILLAN \& CO., LTD.

ST. MARTIN'S STREET, LONDON, W.C.2

Telephone Number: WHITEHALL 883I

Telegraphic Address : PHUSIS, LESQUARE, LONDON

Advertisements should be addressed to

T. G. Scott \& Son, L.td., 63 Ludgate Hill, London, E.C. 4 Telephone Number: City 1266

\section{Financing Research}

QNE of the commonest indictments of the financial structure in Great Britain as compared with, for example, Germany and the United States of America, has been the reluctance of our banking system to make advances for the financing of new industrial enterprises or the reconstruction on modern lines of established industries. There has, indeed, existed a definite gap in our national organisation, to which the Macmillan Committee directed attention, and to close which it suggested the development of a new body or Board of National Investment. Reference has frequently been made to this gap in recent months, notably in a letter to the Prime Minister from Mr. T. D. Barlow, the chairman of the Lancashire Industrial Development Council.

The unanimity with which, at recent general meetings of various important banks, the chairmen have been at pains to stress the importance of scientific research is accordingly the more remarkable and indeed startling, while Mr. J. W. Beaumont Pease, addressing the meeting of Lloyds Bank, made the significant statement that steps to form an organisation to close this gap in our financial structure are actually being taken.

Addressing the shareholders of Martins Bank Ltd. on January 24, Mr. A. A. Paton, for example, quoted examples of successful research in the cotton industry, particularly the recent discovery of a method of treating cotton cloth chemically which renders it practically indistinguishable from silk, and said that this result was directly due to research on scientific lines undertaken in Manchester. It may well establish cotton goods as a rival both to rayon and to silk, and substantially assist our export of cotton cloth in the finer qualities. "This success," said Mr. Paton, "should encourage all industrialists to recognise the important part that scientific research can play in the development and improvement of their production and lead them to a wider realisation of its value to them."

Mr. F. C. Goodenough's address to Barclays Bank Ltd. similarly asserted that the importance of research work in the advance of industry cannot be overestimated. The place to be assigned to the scientific worker in industry is, he said, a factor of the greatest importance which we cannot afford to overlook in the production of high quality goods. We must look forward to the development both of co-operation and individual effort in 
research if the craftsmanship of our workmen is to receive the maximum support of scientific knowledge in facing the present severe world competition. Similarly, the Hon. Rupert E. Beckett, addressing the Westminster Bank on February 2, asserted that we must endeavour by every means at our command to keep abreast of development in existing industries and take advantage of every opportunity to establish new industries. To allow industry to mark time would be fatal. We have a great reserve of scientific and inventive ability and it is essential that, faced as we are with shrinking markets for our products in many directions, we should utilise to the full any opportunities for new development which may be made available to us by scientific investigation. Mr. R. MacKenna's address to the Midland Bank on January 27 also referred to the great attention paid by many firms to scientific research, the value of which can scarcely be overstated, "though there is still room for great advance in this direction. The facilities for such research, through Government establishments, trade organisations and university institutions are greater than ever before and should be used to the full."

In the same strain Sir Christopher Needham told the District Bank Ltd. on January 27 that "A modern competitive industry must regard industrial and technical research as a necessary part of its very structure; only then will it be ready to take full and prompt advantage of improvements which scientific discovery reveals. The benefits of research are not necessarily restricted to big business, for any concern, great or small, which is wise enough to seek it can now find the essential help of this kind at its disposal." Of the cotton industry he added, "To-day more than ever before the cotton industry needs to know all that science can discover about the raw material it uses. The industry is singularly well served by its Research Association at the Shirley Institute and this co-operative effort of the industry to apply science to the production of cotton goods has been more than justified by results." He expressed the hope that the efforts of the scientific workers and technicians will receive that encouragement and help from the industry which they deserve.

Joining in the same chorus, Mr. G. P. Dewhurst also referred to the position in the cotton industry and told the Williams Deacon's Bank Ltd. on the same day that "Facilities for industrial research are available for all and science is fully capable of showing how processes of manufacture may be improved upon and persistent investigation to that end cannot fail to bring its reward".

Sir Harry Goschen's address to the National Provincial Bank Ltd. on January 26 referred to scientific research and the application of its results in industry as being at the root of our power to sell our goods and to meet the needs of our population so far as possible out of our own resources. Slow as the practical man in Great Britain has been on the whole to take full advantage of the products of the laboratory, the greater interest he is now taking in scientific activity is a happy augury for the future welfare of our people. There is room, Sir Harry said, for still closer contact between the industrialist and the scientific worker and this is provided by that useful organisation, the Department of Scientific and Industrial Research.

Mr. J. W. Beaumont Pease's contribution, as chairman of Lloyds Bank Ltd., is sufficiently important to merit quoting in detail. Admitting that a prime condition of industrial recovery is the solution of the difficult international financial problems which confront us, he asserted that that in itself would not ensure the return of prosperity to Great Britain unless we exercise the same resourcefulness and enterprise which our predecessors showed in no less difficult though somewhat different circumstances in the past. "To-day there is probably no direction affording a better prospect of rich reward than scientific discovery. It has to be remembered that the exercise of the native and untutored genius for improvisation and invention which in the past was sufficient to keep us in the van of progress is no longer sufficient. Economic production is to-day a highly expert business requiring the specialised training such as is possessed by the man of science. We must turn more and more to the research worker to point the way towards new advances and industry must realise that an efficient and well equipped research organisation is an essential element of good management."

Referring to the facilities for industrial research which are open to all in Government establishments, trade research associations and university institutions, Mr. Pease, in answer to the argument that only the larger and richer firms can finance such research, agreed that some organisation for providing finance for intermediate loans of modest amounts, and for comparatively short periods, which would fill the gap between ordinary banking loans and those of a longer duration and for 
larger sums, would be a desirable addition to our financial machinery. Steps to form such an organisation, he announced, are actually being taken.

The scientific worker may well rub his eyes in bewilderment and wonder whether the millennium has dawned! That the chairmen of eight large banks should speak in exactly the same strain and in the course of balanced and comprehensive surveys of the national position, in which due regard was had to all the other relevant factors, can scarcely be mere coincidence. The statements regarding the position and importance of research as a factor in national and industrial development could not be bettered and represent an outlook we have consistently urged in these columns for years past. Such sudden and mass conversion of a section of the community renowned for its conservatism cannot but quicken expectations of welcome and beneficial developments in national policy.

To whatever leaven this change of outlook is to be ascribed, whether to the educational work of the Department of Scientific and Industrial Research and other organisations, to the intensity of our present difficulties, or to increased contact with those responsible for developments in Germany, the United States, or Soviet Russia, undue optimism would be premature. On one hand, research is only one factor in new industrial development and the revival of trade is indeed only one of the fields in which scientific thought makes an important if not essential contribution. On the other hand, the present precarious position of the Research Association of British Rubber Manufacturers, which was discussed in Nature of February 11 and 25, reminds us that industry is still very far from accepting research as a fixed charge comparable with obsolescence and insurance.

Plenty of evidence could be found that in other industries also, those in control have yet to learn that there is something to be gained by the application of the results of research. In the cotton industry, more co-operation is still required between the Shirley Institute and the technical staff in the industry. The scarcity of technical men on the directorates and boards of many industries is a common obstacle to the full appreciation of the value of scientific work, and research staffs are often the first to be cut down in times of panic.

There is, however, in such unanimity as is shown by the banking interests, at least the danger that over-emphasis may be laid on the assistance which scientific research can contribute towards recovery. Research is only one factor, and a great expansion in scientific and industrial research is more likely to contribute to our future prosperity than to the relief of our immediate difficulties. What is perhaps even more important at the present moment is that greater use should be made of the results of research already available, and that the scientific spirit and method should be more seriously and widely applied to assist in the handling of those difficult and intricate problems of management, production and distribution, on a national as well as on an international scale, with which industry and politics alike are confronted in a scientific age. It is to be hoped that the scientific outlook indicated in the eight addresses we have quoted will be reflected in the banks themselves according a place to scientific and technical opinion and advice in their counsels. It is only as such steps are taken that we can hope for the appropriate handling of the difficult problems which research inevitably brings in its train. It must be remembered that, from one point of view, scientific and industrial research disturb the stability of our economic and social order. Research tends to a dynamic society the ordering of which makes much greater demands on administrative ability than are made by a static order.

That scientific research should be commended in this manner is at least an encouraging sign. We may hope that such encomium will induce industry generally to apply more wholeheartedly and widely the results of research, to accord technical and scientific men a much more influential place in the conduct of its affairs, if not indeed to demand technical and commercial attainments as essential qualifications for a place on its boards of directors and management. We may hope, too, that the changed outlook will result in far more generous support for fundamental and long-range research, whether conducted in Government institutions or in the universities, upon which in the end even industrial progress depends. There is so much room for improvement in these matters that long before excessive effort has been expended on research, scientific workers themselves should be able to bring home to the community the essential fact that research is only one factor in recovery, one aspect of the fundamental problem of ordering the life of industry and of society in the light of reason and knowledge and not of prejudice. 